\title{
amaro Cavalcanti e os caminhos da industrialização brasileira
}

\author{
Ligia Osório Silva \\ Professora do Instituto de Economia da Unicamp \\ Suzana Cristina Fernandes \\ Doutoranda do instituto de Economia da Unicamp
}

R E S U M O

O propósito deste trabalho é recuperar e sistematizar as manifestações do pensamento industrialista brasileiro no final do Império e na primeira década republicana, através do intelectual e político Amaro Cavalcanti, considerado pela historiografia um dos seus principais representantes no período. Ao longo da sua vida, Amaro Cavalcanti nunca deixou de acreditar que a industrialização seria o remédio para os males existentes na sociedade brasileira e, como político no Congresso Nacional, não poupou esforços para defender suas idéias e reivindicar uma política econômica que protegesse as indústrias nascentes.Através de uma leitura crítica de suas obras econômicas, procuramos entender melhor suas idéias, suas reivindicações e seus argumentos relacionados ao protecionismo e ao papel do Estado na economia. Com isso, pretendemos não apenas resgatar 0 pensamento um tanto esquecido de um lídimo representante da corrente industrialísta na virada do século, mas também situar suas idéias sobre a industrialização em perspectiva histórica.

Palavras-chave: Brasil, Império, República, política econômica, industrialização.
A B S T R A C T

The purpose of this paper is to recover and to systematize the manifestations of Brazil's industrialist thought at the end of Empire and during the Republic's first decade, through the ideas of the intellectual and politician Amaro Cavalcanti, viewed by historiography as one of its main representatives in that period. During his lifetime, Amaro Cavalcanti never ceased to believe that industrialization would be the cure for all existing evils within Brazilian society, and, as a politician in the National Congress, he did not spare efforts in defending his ideas and in arguing for the adoption of economic policies geared to the protection of the country s infant industries. Through a criticai assessment of his economic works, we attempt to better understand his ideas, pleas and arguments related to protectionism and to the State's role in the economy. By doing this, we intend not only to rescue the thoughts of a representative of industrialism at the beginning of the twentieth century, but also to situate his ideas on Brazil's industrialization within a historical perspective.

Key words. Brazil, Empire, Republic, economic policy, industrialization.

A pesquisa que deu origem a este trabalho contou com o apoio financeiro da Fapesp. 


\section{Introdução}

A indústria brasileira tem uma história muito recente quando comparada não apenas à da Inglaterra, berço da Revolução Industrial, mas também à de outros países da Europa, como a França e a Alemanha, e à dos Estados Unidos, países que já estavam plenamente industrializados nas últimas décadas do século XIX. No Brasil, apesar das primeiras tentativas de instalação de fábricas datarem do século XVIII, a industrialização como processo surgiu apenas na segunda metade do século XIX, expandindo-se a partir da década de 1880 , intimamente articulada à expansão cafeeira, e só passando a ter um papel importante na década de 1920 , quando chegou a se formar um respeitável parque industrial de bens de consumo.

Paralelamente a este desenvolvimento industrial, e até muito antes dele, a historiografia brasileira registra inúmeros esforços, representados por alguns nomes eminentes ligados ou não à indústria, os quais reivindicavam uma política protecionista para a indústria nacional, por acreditarem que somente através da industrialização poderia o Brasil alcançar o seu desenvolvimento econômico. Esses esforços, inicialmente esporádicos, foram sufocados na primeira metade do século XIX, por força das influências internacionais e pela indiferença da classe dominante, ainda fortemente comprometida com os interesses agrários. Contudo, as grandes transformações econômicas que ocorreram a partir de meados daquele século, decorrentes da rápida acumulação de capital no contexto da expansão cafeeira, provocaram uma série de mudanças nos aspectos político, econômico, cultural e social do País, e tornaram o clima mais propício às manifestações nacionalistas pelo desenvolvimento.

Os debates sobre a industrialização brasileira, centrados nas políticas protecionistas, intensificaram-se na década de 1880 , em função das crises econômicas que atingiram as indústrias já existentes. A partir desse momento, o pensamento industrial ganhou solidez e assumiu a forma de um movimento coletivo. Surgiram, nesse período, defensores da indústria nacional, lutando por uma política protecionista que auxiliasse o desenvolvimento industrial. Neste grupo, além de alguns empresários, encontravam-se também intelectuais, políticos e parlamentares, muitas vezes, sem qualquer vínculo direto com a indústria, mas partidários do crescimento industrial como meio de desenvolver o País. Entre estes se destacaram: Antonio Felício dos Santos, Amaro Cavalcanti, Serzedelo Correa, Alcindo Guanabara,João Luiz Alves e Jorge Street.

O propósito deste trabalho é,justamente, compreender as propostas 
do pensamento industrialista nos últimos anos do Império e na primeira década republicana, através da análise das idéias de um dos representantes desta corrente, o intelectual e político Amaro Cavalcanti. A escolha de Amaro Cavalcanti sejustifica não apenas porque ele é considerado pela historiografia como um dos mais expressivos representantes desta corrente de pensamento, mas porque o seu perfil revela um homem de grande cultura, político atuante, autor de numerosas obras sobre a economia brasileira. Foi uma presença combativa no Congresso Nacional, a favor da indústria, desenvolvendo uma trajetória bastante coerente e, no entanto, sua contribuição não tem sido devidamente realçada na história da luta pela industrialização brasileira.

\section{Vida e obra de Amaro Cavalcanti}

Amaro Cavalcanti nasceu em 1849 numa família de poucos recursos no município de Caicó no Rio Grande do Norte. ${ }^{2}$ Estudou a duras penas até conseguir tornar-se professor de Latim, Inglês e Francês na Escola Popular de Baturité em 1872. Enquanto professor escreveu alguns livros sobre educação e, graças a estes trabalhos e sua dedicação ao magistério, o governo cearense, através de seu presidente Pedro LeãoVeloso, comissionou-o para estudar o sistema de instrução elementar nos Estados Unidos, com o intuito de elaborar uma reforma da instrução pública aplicável àquela Província. Nos Estados Unidos, aproveitou a oportunidade para matricular-se na Escola de Direito da Union University em Albany (N.Y.) e em dois anos, segundoVelho Sobrinho (1937:330331 ), já era o primeiro aluno da turma, conquistando o título de Counsellor at Law, em 1881 com a tese: Is education a legal obligation?, título que lhe dava o direito de exercer a profissãojurídica em todo o território dos Estados Unidos, tendo sido o primeiro brasileiro a gozar deste direito. De volta ao Brasil, o presidente da Província nomeou-o, em outubro de 1881, Diretor do Liceu de Humanidades e InspetorGeral da Instrução Pública do Ceará, cargo que hoje corresponderia ao de Secretário da Educação.

Existem nas diversas biografias sobre Amaro Cavalcanti algumas divergências quanto à sua data de nascimento, mas, segundo informações de seu neto o Embaixador José Carlos Cavalcanti Linhares, esta é a data correta.Também é freqüente a confusão que se faz entre Amaro Cavalcanti e Amaro Bezerra Cavalcanti, também político durante o Império, nascido em Pernambuco em 1825 e falecido em 1890, mas entre eles não há qualquer relação maior do que a coincidência de nomes. 
Além da formação acadêmica, Amaro Cavalcanti aproveitou nos Estados Unidos a rica experiência social e cultural de conhecer in loco um país em plena fase de desenvolvimento industrial, engajado na via de um progresso contínuo e duradouro. O contraste com a situação que prevalecia no Brasil, que na sua opinião era de decadência e atraso econômico, certamente teve influência sobre a postura crítica que assumiu em relação aos problemas econômicos e sociais nacionais e determinou, em parte, a sua atuação política posterior.

Ao longo da década de 1880 , Amaro Cavalcanti dedicou-se a analisar a economia brasileira de modo comparativo com a economia norteamericana, procurando elaborar alternativas para colocar o Brasil na via do desenvolvimento. Para ele, tudo aproximava o Brasil dos Estados Unidos, pois ambos tinham características históricas e geográficas semelhantes: eram possuidores de vastos territórios com uma grande diversidade de recursos naturais, e eram ambos ex-colônias; no entanto, a realidade mostrava que o Brasil encontrava-se muito mais atrasado. Enquanto que os Estados Unidos trilhavam o caminho do desenvolvimento industrial, o Brasil seguira um caminho inverso, especializandose na produção de bens primários de baixo valor agregado. Contudo, ainda estava em tempo de o País reverter este quadro, superar a condição de produtor estritamente agrícola e lançar-se rumo ao desenvolvimento econômico, percorrendo a trilha do exemplo norte-americano. Mas, isto só seria possível através do desenvolvimento industrial. Engajouse, então, na luta pela industrialização.

Além da sua experiência nos EUA, Amaro Cavalcanti foi influenciado pelo movimento industrialista que já se formava a partir do último quartel do século XIX, depois do agravamento da instabilidade econômica, gerada pela crise internacional que atingiu o Brasil em 1874/75. A vulnerabilidade da economia brasileira frente à crise, despertou a preocupação de alguns intelectuais brasileiros, intensificando as manifestações nacionalistas a favor de uma política protecionista e intervencionista que fosse capaz de dar sustentação ao desenvolvimento da indústria. O ideário nacionalista embasava esse movimento coletivo, que reunia industriais, intelectuais e parlamentares em torno de atividades panfletárias - discursos, artigos emjornais e revistas - e em torno da criação de associações voltadas para a difusão da necessidade de políticas econômicas que favorecessem o desenvolvimento nacional.

Amaro Cavalcanti passou a fazer parte desse movimento e ganhou nessa luta o status de um dos maiores representantes do pensamento 
industrialista brasileiro do final do século XIX. ${ }^{3}$ Imbuído do ideário nacionalista e das idéias protecionistas de Friedrich List, ${ }^{4}$ por um lado, e entusiasmado com o desenvolvimento norte-americano, pelo outro, Amaro Cavalcanti dedicou-se ao estudo da economia brasileira, escrevendo alentados trabalhos sobre a situação financeira do País, com muita riqueza de detalhes. Engajou-se na vida política e na luta pela industrialização, com o objetivo precípuo de encontrar alternativas para colocar o Brasil na via do desenvolvimento e reproduzir aqui o sucesso econômico verificado nos Estados Unidos.

Durante sua longa carreira política, Amaro Cavalcanti foi vice-governador do Rio Grande do Norte, nomeado em 1889 por decreto do Governo Provisório. Em setembro de 1890 , foi eleito por aquele Estado Senador no Congresso Constituinte da Primeira Legislatura (15/06/ 1891 a 25/09/1893), fazendo parte da Comissão dos 21 que formulou a primeira Constituição da República. Sua atuação no Congresso foi intensa, participando de todas as discussões relativas a assuntos financeiros e econômicos, colocando-se frontalmente contra a política oligárquica e descentralizadora dos conservadores. Amaro Cavalcanti foi eleito deputado pelo Rio Grande do Norte naTerceira Legislatura (1897-1899), renunciando logo em seguida ao mandato ao ser chamado pelo Presidente Prudente de Moraes para a pasta do Ministério da Justiça e Negócios Interiores. Em 1902, a pedido de Rodrigues Alves, ocupou

Cf. Nícia Vilela Luz, A Luta pela Industrialização no Brasil, São Paulo:Alfa Omega, 1978; Humberto Bastos, O Pensamento Industrial no Brasil, São Paulo, 1952; Heitor Ferreira Lima, História do Pensamento Econômico no Brasil, São Paulo, Ed. Nacional, 1978; Edgar Carone, O Pensamento Industrial no Brasil (1889-1945), São Paulo; Difel, 1977;Doríval Teixeira Vieira,A Obra Econômica de Amaro Cavalcanti, São Paulo: FEA, 1960 .

Mesmo a época áurea do liberalismo na Europa não eliminou o protecionismo de tipo mercantilista. Mas, cada vez mais, no século XIX, o protecionismo veio associado ao nacionalismo. Friedrich List é considerado a figura mais proeminente do pensamento industrialista nacionalista. Sua principal obra The National System of Political Economy (1841, tradução brasileira de 1986), alçou-o à posição de autoridade na matéria, em especial na Alemanha, onde sua influência remonta aos anos 1810 . List escreveu na primeira metade do século XIX sobre a necessidade de se proteger as infant industries (expressão cunhada por Alexander Hamilton) até que elas fossem capazes de enfrentar com vantagem a competição internacional. Mas, é preciso notar, segundo Paul Bairoch, que a escola moderna de pensamento protecionista, aquela conectada ao período posterior à Revolução Industrial nasceu nos Estados Unidos. Cf. Economics and World History. Myths and Paradoxes, New York: Harvester Wheatsheaf, 1993 , p. 17,23 e 33. 
o cargo de ConsultorJurídico do Ministério do Exterior, onde permaneceu até 1906. Nesse ano foi nomeado Ministro do Supremo Tribunal Federal, cargo que ocupou até 30/12/1914. Durante o Governo de Wenceslau Braz, foi nomeado prefeito do Distrito Federal, exercendo o cargo cercado de grande prestígio, de 1917 a 1918. Em 15/11/1918 assumiu como Ministro da Fazenda e Interino da Justiça a convite do Presidente Rodrigues Alves, cargo que exerceu até a morte do Presidente em 16/01/1919.5 Amaro Cavalcanti faleceu em 28 dejaneiro de 1922 no Rio de Janeiro. ${ }^{6}$

Como se depreende do que foi dito acima, Amaro Cavalcanti não era um industrial e, portanto, não advogava em causa própria; sua luta em prol da industrialização tinha um cunho eminentemente nacionalista - ou seja, seu objetivo era ver o Brasil ocupar a mesma posição alcançada pelos países industrializados do (hoje) chamado Primeiro Mundo.

As obras deixadas por Amaro Cavalcanti são bastante numerosas e contêm importantes referências históricas e um grande acervo de idéias ligadas a diversas áreas, tais como: direito, religião, educação, economia e finanças. Todavia, restringimos nosso interesse às obras ligadas à área

Além desses cargos políticos Amaro Cavalcanti participou, como membro da Comissão Parlamentar, na elaboração do Projeto do Código Civil e foi nomeado delegado na $3^{\text {a }}$ Conferência Pan-Americana, reunida na Capital Federal em 1906. Foi designado delegado do Brasil na Conferência Financeira Pan-Americana, realizada em Washington em 1915 e em 1917, e no ano de 1918 foi escolhido representante do Brasil no Tribunal Arbitrai de Haia. Graças a suas numerosas publicações, foi eleito em 06/12/1897 sócio efetivo do Instituto Histórico e Geográfico Brasileiro. Entre os cargos ocupados por Amaro Cavalcanti figuram ainda a fundação e direção como Presidente da Sociedade Brasileira de Direito Internacional em 1914, membro honorário do Instituto dos Advogados, do Instituto Histórico Brasileiro, do Instituto Histórico do Rio Grande do Norte, Professor de Finanças da Academia de Altos Estudos. Além disso, falava e escrevia corretamente o inglês, francês, alemão, espanhol, conhecia o italiano e o holandês, e estudou russo. (Cf. José Augusto," Amaro Cavalcanti". Rio de Janeiro: Departamento Administrativo do Serviço Público, 1956; Enciclopédia e Dicionário Internacional vol. I e IV, Rio de Janeiro: W. M.Jackson Editora, s/d.; Revista do Instituto Histórico e Geográfico Brasileiro, Rio de Janeiro: Imprensa nacional, tomo 92, vol. 146, 1926, p.592-594, tomo LXXV,parte II, 1912 e tomo LX, parte I, 1897; J.F. Velho Sobrinho. Dicionário Biobibliográfico Brasileiro, Rio de Janeiro: Pongettio, 1937, p. 330-331; Dorival Teixeira Vieira, A Obra Econômica de Amaro Cavalcanti, op. cit. passim.)

Mais informações sobre a extensa carreira política de Amaro Cavalcanti podem ser encontradas em Suzana Cristina Fernandes, Amaro Cavalcanti e a Luta pela Industrialização Brasileira, dissertação de Mestrado apresentada ao Instituto de Economia da Unicamp (Campinas, 2001). 
econômica e financeira, nas quais o Autor exprimiu seu vasto conhecimento sobre a economia brasileira e suas idéias sobre o desenvolvimento nacional.' A maior parte de sua obra econômica está concentrada na década de 1890, período em que atuou mais ativamente no cenário político. Seus trabalhos são geralmente extensos, ricos em descrições de acontecimentos, baseados em documentação primária. Na maioria dos seus trabalhos predomina o senso crítico sobre a situação econômica do Brasil, nas suas avaliações sobressai o espírito de combatividade que 0 anima, mas por vezes nota-se, também, uma atmosfera de contemporização. Amaro Cavalcanti pode ser descrito como otimista uma vez que, embora reconhecendo as deficiências e as dificuldades brasileiras, sempre encontrava uma proposta ou solução para os problemas e para o desenvolvimento econômico do País, acreditando firmemente na sua capacidade de erguer-se economicamente ao nível dos países desenvolvidos.

O final do Império e os primeiros anos da República, período que compreende a crise do Encilhamento, foram a fase mais atuante de Amaro Cavalcanti na sua luta industrialista. Naquele momento, sua participação foi bastante destacada, tanto nas discussões dos projetos de reforma monetária, em que defendia uma política mais liberal de expansão do crédito para os investimentos industriais, quanto nas discussões sobre ajuda financeira e proteção tarifária para as indústrias atingidas pela crise, contrapondo-se frontalmente à bancada conservadora do Império. Seus discursos no Congresso Nacional constituem uma importante fonte de referência para conhecermos seu pensamento, suas reivindicações e seus argumentos a favor da indústria nacional.

\footnotetext{
Muito poucos estudos fazem alusão ao pensamento econômico de Amaro Cavalcanti, sendo que o único trabalho conhecido que vai além de uma simples biografia, é de Dorival Teixeira Vieira, A Obra Econômica de Amaro Cavalcanti, publicada em 1960, no qual se fez um sério trabalho de análise do pensamento econômico desse autor.

Na elaboração deste trabalho utilizamos as seguintes obras de Amaro Cavalcanti: Resenha Financeira do Ex-Império do Brasil em 1889 (de 1890); O Meio Circulante Nacional (1808-1835), (de 1893); Elementos de Finanças. Estudos Theórico-Práticos, (de 1896); e os artigos: "Taxas protetoras nas tarifas aduaneiras" (de 1903) e "A vida econômica e financeira do Brasil" (de 1914); além dos seus discursos no Congresso Nacional, reunidos no livro Política c Finanças, publicado em 1892.
} 


\section{A identificação dos problemas nacionais}

Amaro Cavalcanti via três aspectos problemáticos na economia brasileira do final do século XIX. O mais evidente deles era a absoluta dependência do País em relação ao exterior, mesmo após quase um século de independência política. De fato, na virada do século, a economia brasileira sofria de profundos desequilíbrios macroeconômicos, provocados por alterações bruscas na posição do seu principal produto no mercado internacional. A extrema vulnerabilidade da economia primário-exportadora brasileira devia-se, em primeiro lugar, às flutuações abruptas da oferta de café, resultantes das variações climáticas sobre a produtividade dos cafezais. Dado o peso deste produto no valor das exportações, as variações na oferta de café tendiam a reduzir drasticamente a receita das exportações. Em segundo lugar, estavam as perturbações na economia internacional, notadamente as flutuações na demanda dos países centrais e as bruscas interrupções do fluxo de capitais em direção à periferia, que foram freqüentes nas primeiras décadas do século (Franco, 1989:35). Em conseqüência disso, restringia-se a capacidade do País importar e acentuava-se o seu desequilíbrio fiscal. Para Amaro Cavalcanti, era constrangedor que um país do porte do Brasil tivesse que depender deste modo do exterior e importar boa parte dos bens de consumo necessários à sua população, quando, do ponto de vista dos recursos naturais, teria condições de produzir internamente e satisfazer a demanda do mercado interno com seus produtos, sem depender de empréstimos estrangeiros e sem sofrer os percalços provocados pela dependência num único produto exportável.

"Não obstante o caso feliz de nos haver tocado por sorte um território que a nenhum outro cede em boas condições ou fontes de riqueza natural - continuamos, todavia, na dependência das outras nações em quase tudo que respeita ao desenvolvimento material do país e até as necessidades do nosso viver quotidiano! (...) vivemos hoje, como nos tempos coloniais, a importar do estrangeiro quase absolutamente tudo o que consumimos, não obstante podermos sabidamente havê-lo, ao menos em grande parte, da produção nacional". (Cavalcanti, 1920:12)

Este estado de dependência era para Amaro Cavalcanti conseqüencia de uma série de problemas que remontavam à economia dos tempos coloniais, e que o Império, apesar dos meios disponíveis, não fora capaz 
de solucionar. Sua conclusão, ao avaliar esta situação, era de que faltou ao País "o vigor crescente das forças econômicas", ou seja, o trabalho consciente pelo desenvolvimento das forças produtivas. Em conseqüência, o País chegou ao final do século XIX com uma estrutura produtiva obsoleta e insuficiente para atender, ao menos, as necessidades internas de consumo da população, tendo que importar bens de consumo que poderiam ser facilmente produzidos internamente. Atribuía o pífio resultado até então alcançado pela economia brasileira às más administrações governamentais e ao baixo interesse das classes dirigentes em formar as bases para a produção de riqueza, sempre mais preocupadas com os "interesses mesquinhos da política" do que com o engrandecimento da pátria.

Tais problemas foram causados, em última instância, pela falta de uma política consciente de desenvolvimento de fontes produtoras de riqueza, que fossem capazes de garantir não apenas o sustento da nação, no que se refere às necessidade cotidianas, mas também que garantisse o crescimento da renda geral do Estado, de forma a consolidar o crédito público e equilibrar as contas nacionais. Para ele, a existência de setores produtivos eficientes e rentáveis era uma condição fundamental para o progresso e o engrandecimento do País. Assim dizia: "nenhum povo poderá ser grande, respeitado e feliz nas suas relações, seja de ordem interna, seja de ordem externa, sem a condição essencial de possuir riqueza sua própria, ao menos suficiente para acorrer ás necessidades normais do Estado e das diversas classes da sociedade" (Cavalcanti, 1920:13). Neste sentido, a produção de um país deveria ser ao menos suficiente para atender a sua demanda interna e, mesmo que não pudesse ofertar todos os produtos necessários à sua população, era preciso produzir o bastante para gerar uma renda ao Estado para cobrir as despesas no exterior com a aquisição dos produtos importados.

A soma dos dois problemas anteriores refletia-se na situação do balanço de pagamentos. Assim, Amaro Cavalcanti chegava na questão que da sua ótica era a fundamental: eliminar os problemas do balanço de pagamentos e o desequilíbrio financeiro do Estado. A história do balanço de pagamentos do Brasil no século XIX revelava um estado de permanente desequilíbrio, não obstante o saldo favorável da balança comercial alcançado com a expansão das exportações cafeeiras. Os déficits do balanço de pagamentos eram freqüentemente compensados pela entrada de capital estrangeiro na forma de investimentos diretos, de empréstimos externos ou através da emissão de papel-moeda. Entretanto, em períodos de crise interna ou externa, a tendência era a fuga dos capitais estrangeiros 
ou a dificuldade de atrair capital externo, e isto gerava dificuldades financeiras para o País, como o aumento da dívida pública, tanto pelo aumento dos empréstimos públicos contraídos para conter o déficit, quanto pelo crescimento da taxa de juros que onerava ainda mais os encargos da dívida externa (Marcondes, 1998:540-542).

Para Amaro Cavalcanti, uma forma de superar esses problemas do balanço de pagamentos era desenvolver os setores produtivos internos, de modo que a produção se expandisse o bastante para atender o mercado nacional, diminuindo as importações, e ao mesmo tempo ultrapassasse a demanda interna para que o excedente fosse exportado. E, no seu entender, o único setor produtivo capaz de garantir esse resultado não era a agricultura nem a indústria extrativa, os setores que até aquele momento mais contribuíam para a economia brasileira, e sim a indústria. Para ele, o setor agro-exportador sozinho não seria capaz de levar o País a alcançar o progresso econômico. Daí sua ênfase na necessidade de desenvolver os setores industriais que dariam novo dinamismo à economia, aumentando a geração de renda interna.

O desequilíbrio do balanço de pagamentos foi certamente um dos pontos mais atacados pelos industrialistas para pleitear uma política de proteção industrial. Felício dos Santos defendia na Câmara dos Deputados, em 1881, que os desequilíbrios financeiros do Estado não podiam mais ser enfrentados com paliativos, como empréstimos e emissões; a saída, para ele, também era o fomento da produção nacional, especialmente a da indústria. Assim dizia:"Adotar (...) medidas que diminuam importação enquanto não se eleva a exportação. Isso importa proteção à indústria nacional, que há de suprir grande parte da importação." (Luz, 1958:307).Serzedelo Corrêa, em 1903, retomava esse argumento, afirmando que a nossa dependência externa comprometia nossa soberania. Dizia:

"Cerca de 85 por cento da atividade comercial não nos pertence e não ficam no país; os fretes da navegação, os lucros e dividendos de bancos, de empresas de seguros de toda a espécie, de aluguéis de prédios, o salário devido ao trabalho nas fazendas de café, etc, tudo, tudo isso em larga escala, aqui não fica e sai do excesso do valor de nossa produção agrícola sobre o valor do que importamos." (Corrêa, $1903: 5-6)$

A saída era desenvolver a indústria nacional para aumentar a produção interna e evitar a drenagem da riqueza para o exterior. 
Enfim,para os industrialistas,o desenvolvimento da indústria nacional faria diminuir as importações e, conseqüentemente, os encargos relacionadoos a ela, como fretes, seguros, etc., reduzindo as despesas do governo no exterior e aumentando, de certa forma, a disponibilidade de recursos para serem investidos na expansão da produção local.

Para Amaro Cavalcanti, a indústria, a "classe produtora por excelência", pelas suas características particulares tinha um efeito multiplicador de riqueza que nenhum outro setor teria. Era o setor por excelência em condições de, em primeiro lugar, satisfazer o mercado interno em expansão - de acordo com Amaro Cavalcanti era possível observar o papel dinâmico do crescimento do mercado interno através das mudanças recentes na economia. O aumento do consumo interno, por exemplo, principalmente nos anos de 1891 e 1892 , era resultado do crescimento da população em virtude da imigração estrangeira, da organização de novas empresas e companhias que demandavam mais casas, escritórios, fábricas e oficinas, e objetos de consumo; era também conseqüência do aumento da renda interna, que elevava e diversificava as necessidades de consumo (Cavalcanti, 1892:357-358).Em segundo lugar, era o setor capaz de fortalecer com eficácia o comércio internacional através da substituição das importações pela produção interna e pelo aumento das exportações de produtos com maior valor agregado; e, finalmente em terceiro lugar, era o único setor em condições de aumentar a renda do Estado, através do aumento da arrecadação de impostos, diminuindo a dependência do estrangeiro, equilibrando as contas públicas do País e garantindo, assim, a soberania nacional. Enfim, a indústria era uma garantia de prosperidade financeira:"a prosperidade financeira não tem base mais sólida, mais larga, nem mais garantidora, do que o desenvolvimento progressivo da indústria nacional" (Cavalcanti, 1892:326).

Contudo, apesar do"...verdadeiro progresso econômico de um povo (dever) ser procurado nos seus recursos ou melhoramentos industriais", este importante fator de progresso esteve sempre relegado a um segundo plano no Brasil, sendo até mesmo impedido de se realizar por força de inúmeros empecilhos e oposições (Cavalcanti, 1890:197).

Naturalmente, o primeiro grande empecilho ao desenvolvimento das forças industriais no País era a condução da economia pautada pelos interesses agro-exportadores. Durante quase todo o século XIX, a política econômica esteve orientada pelos interesses agrário-comerciais da camada dominante, os quais relegavam a segundo plano e impunham certos limites ao desenvolvimento industrial. Em outros termos, no final do século XIX, os interesses industriais estavam subordinados aos 
interesses agrário-comerciais, principalmente cafeeiros. Os maiores obstáculos à industrialização residiam, portanto, na falta de interesse das classes dominantes em desenvolver políticas que favorecessem a indústria nacional, e na oposição do setor agrário e do comércio às políticas de proteção industrial.

No campo econômico, os maiores entraves à industrialização decorriam da falta de recursos financeiros e da escassez de meio-circulante e de crédito fácil. A administração da política monetária marcadamente conservadora durante o Império, e conduzida pela meta da conversibilidade e por um contínuo viés deflacionista, com alguns períodos de exceção, conduziu a economia a um grande aumento da dívida pública e a um sistema econômico em regime de permanente escassez de meios de pagamento, tornando escassos os recursos a serem investidos na indústria.

A falta de mão-de-obra e a permanência do escravismo foram outros grandes obstáculos à industrialização do País. Para Amaro Cavalcanti, a condescendência do Governo para com o sistema escravista comprometeu o desenvolvimento do País. Sobre isso dizia:

"Este fato impossibilitou-nos durante muito tempo a imigração estrangeira, e daí o retardamento da nossa vida industrial. Muitas medidas econômicas e financeiras deixaram de ser estudadas ou atendidas, muitos alvitres utilíssimos foram menosprezados, uns com relação direta ao problema urgente de transformação do trabalho, outros com relação ao sistema econômico-financeiro, em geral - porque envolviam a necessidade de resolver a questão inadiável da abolição do trabalho escravo!" (Cavalcanti, 1890:40)

Outras dificuldades impostas ao desenvolvimento industrial, segundo Amaro Cavalcanti, eram a precariedade dos sistemas de transportes nacionais e a vigência de impostos interestaduais, entraves à livre movimentação de mercadorias por todo o território nacional. Instruído pelo exemplo norte-americano, atribuía grande importância econômica às redes de transportes, e por isso defendia a necessidade de se construir novas estradas rodoviárias, novas vias férreas e de se melhorar as condições dos portos e da navegação fluvial e marítima. Por outro lado, a regulação do sistema de impostos interestaduais era indispensável para que as mercadorias pudessem circular livremente, completando a integração do mercado interno.

As críticas de Amaro Cavalcanti ao sistema de transporte nacional estão em seu 
Apesar desses entraves, as indústrias nacionais surgiram aos poucos e foram ganhando peso no cenário econômico, principalmente nos últimos anos do Império. Após a Proclamação da República, mudaram algumas condições essenciais da economia que, em geral, beneficiaram o setor industrial. Em particular, fizeram-se sentir positivamente os efeitos da abolição da escravidão e do significativo crescimento da imigração na década de 1890 . As políticas monetárias e fiscais expansionistas também contribuíram para o clima de otimismo do setor. Em conseqüência disso, aumentou ainda mais o empenho dos industrialistas que defendiam uma política protecionista no Congresso Nacional e na grande imprensa.

Contudo, muito mais precisava ainda ser feito a favor da indústria com o objetivo de alcançar um desenvolvimento industrial semelhante ao dos Estados Unidos. Para Amaro Cavalcanti, a solução consistia na adoção de uma política consciente do Estado para promover a industrialização do País.

Ele estava ciente, no entanto, de que as circunstâncias em que se desenvolvia a industrialização do Brasil no início da República não eram as mesmas vividas pelos países que o antecederam no processo. Percebia que as mudanças no padrão tecnológico das indústrias e as transformações do capitalismo ocorridas no final do século XIX tornavam o desenvolvimento industrial no Brasil muito mais complexo. Por outro lado, também tinha consciência de que estas transformações do capitalismo, que provocaram alterações nos padrões das relações internacionais, acirrando a concorrência intercapitalista, também haviam intensificado o uso das políticas protecionistas como instrumento de defesa da indústria nacional. Sobre isso dizia no Congresso Nacional em julho de 1892:

"Atenda agora o Senado: todas as nações que nos precederam no desenvolvimento da indústria, que já tem bastante riqueza acumulada, para bem satisfazer as necessidades da sua vida ordinária —, todas elas, não obstante, entenderam, neste último decênio, que deviam formar uma nova política financeira internacional, fechando a era das teorias livre-cambistas, e entrando, resolutas, em fase abertamente protecionista, caracterizada pela guerra das tarifas aduaneiras." (Cavalcanti, $1892: 344)$

livro Resenha Financeira do Ex-Império do Brasil, e suas considerações sobre os impostos interestaduais estão no livro Regime Federativo e República Brasileira. 
Sob este aspecto, Amaro Cavalcanti demonstrou ser um arguto observador da economia internacional, pois, não obstante a continuada defesa do liberalismo econômico nos discursos dos economistas e políticos da época, o período 1879-1892 caracterizou-se de fato por um gradual retorno dos países europeus às políticas protecionistas e à manutenção do protecionismo estrito que os Estados Unidos vinham adotando desde 1861 (Bairoch, 1993:34).

Estas circunstâncias reforçavam sua convicção de que a fase vivida pelo sistema capitalista mundial obrigava à intensificação da presença do Estado na economia, única forma de ultrapassar as dificuldades do momento. O Estado devia incentivar e proteger a indústria nacional e criar as condições para que esta se desenvolvesse de forma segura e eficiente, trazendo o progresso para o País. Esta sendajá fora trilhada, em diferentes momentos, pelos países industrializados: os Estados Unidos, a Alemanha e oJapão, em algum momento das suas trajetórias contaram com o apoio do Estado para garantir a industrialização. Durante toda a década de 1890 Amaro Cavalcanti reivindicou a adoção de uma política de proteção eficiente e conseqüente por parte do Estado brasileiro para desenvolver a indústria nacional, mas que fosse, ao mesmo tempo, uma política de fortalecimento da iniciativa privada.

\section{A política econômica industrialista}

Toda a questão se resumia no modo pelo qual a intervenção estatal se daria. Na sua opinião, a atuação do Estado deveria, em primeiro lugar, confinar-se à criação de indústrias essenciais nos setores em que a iniciativa privada não pudesse ou não quisesse investir; em segundo lugar, desenvolver uma política tarifária adequada, capaz de proteger certas indústrias da concorrência estrangeira; e, por último, facilitar os recursos na forma de moeda e crédito para serem investidos no desenvolvimento industrial.

Como Freidrich List, Amaro Cavalcanti defendia uma política protecionista a favor da indústria nascente, nos setores onde esta se mostrasse lucrativa. Cavalcanti acreditava que a proteção era indispensável para a industrialização de um país pobre, mas defendia um protecionismo moderado, seletivo, circunstancial e limitado. Em outros termos, pensava que o moderno protecionismo, em contraste com aquele que vigorara na época mercantilista, não visava criar monopólios, mas garantir o progresso industrial da nação, isto é, a política econômica era vista por ele como parte integrante de uma política nacionalista. A seguir analisamos algumas das suas propostas de política econômica. 


\section{A política tarifária}

Enquanto instrumento de proteção industriada questão tarifária era o "pomo da discórdia" da política econômica, pois envolvia um complexojogo de interesses entre industriais, Estado, comerciantes importadores e cafeicultores. Aos industriais interessava uma tarifa aduaneira elevada que os protegesse contra a concorrência estrangeira dos manufaturados importados; o Estado defendia tarifas elevadas por motivos fiscais; os comerciantes queriam baixos índices tarifários porque tornavam os produtos importados mais baratos e facilitavam seu monopólio sobre o mercado interno e, finalmente, os cafeicultores eram contra tarifas elevadas porque aumentavam os custos dos bens de consumo e equipamentos usados na lavoura e porque temiam represálias dos países compradores de café, insatisfeitos com as tarifas brasileiras. E ainda existiam as pressões vindas do estrangeiro, como bem exemplificou Humberto Bastos comentando o caso do artigo publicado nojornal londrino The Times de 4 de agosto de 1904, quando estava em discussão a reforma tarifária de João Luiz Alves, que acabou não sendo aprovada. Dizia o artigo:

"Em vista da adoção pela Câmara em primeira discussão do projeto relativamente a uma elevação proibitiva das tarifas aduaneiras, sem consulta da Comissão de Orçamento, os representantes diplomáticos da Grã-Bretanha, Alemanha, Áustria-Hungria, Bélgica, Estados Unidos, França e Itália, coletivamente, exprimiram a esperança de que o Governo use de sua influência sobre o Congresso, para manter as velhas tarifas." (Bastos, 1952:79)

Sofrendo todo tipo de pressão, pelo menos até a década de 1930, a questão tarifária no Brasil sempre foi objeto de intensas disputas; ao longo do Império e da Primeira República, cada tentativa de reforma desencadeou acalorados debates. Dada a impossibilidade de conciliar tantos interesses antagônicos, a política tarifária brasileira oscilou durante todo o período entre políticas protecionistas e livre-cambistas, desagradando a gregos e troianos.

A maioria das tarifas aduaneiras de caráter protecionista foi, na verdade, adotada com intuitos puramentefiscais. Compreende-se que o interesse fiscal preponderasse, uma vez que a arrecadação aduaneira representava mais da metade da receita geral. Em meados do século XIX, a reforma Alves Branco elevou fortemente a taxação, mas, em 1857, seguiu-se 
uma tarifa mais liberal. A proteção tarifária aumentou na década de 1880, reforçada pela depreciação da taxa de câmbio em 1880-86. Rui Barbosa, em 1890, seguiu a diretriz protecionista, mas a sua reforma foi bastante criticada, em vista dos prejuízos fiscais que acarretou a redução dos direitos que incidiam sobre as matérias-primas necessárias à produção nacional. Bernardino de Campos diminuiu os direitos de entrada em 1897 e, a partir de 1900 , entrou em vigor a tarifa (rebaixada) de Joaquim Murtinho. Por outro lado, também era verdade, como afirma Nelson Werneck Sodré, que "tarifas não criam indústrias" (Werneck, 1978:88; Suzigan, 2000:82-87).

Amaro Cavalcanti tinha uma posição eminentemente crítica em relação ao sistema tarifário brasileiro, exatamente porque este não tinha caráter definido - nem era liberal, nem era protecionista, mais propriamente elaborado com finalidades fiscais, para cobrir os déficits do Tesouro. Nenhuma política tarifária realmente séria havia sido elaborada a longo do século XIX. Em assunto de tarifas aduaneiras, dizia ele,"estamos nas mesmas condições do tempo do Império" (Cavalcanti, 1903:36).

Para evitar um protecionismo inconseqüente, urgia reparar o nível de proteção tarifária com cuidado e, portanto, antes de se realizar qualquer reforma, uma série de fatores deveriam ser analisados e pesados para que fosse possível separar os efeitos favoráveis dos prejudiciais. A definição de um sistema tarifário exigia assim, um estudo paciente " com toda imparcialidade, com todos os dados estatísticos e outros elementos de informações e comparações, colhidos no país e no estrangeiro, de modo que se lhe pudesse dar sem eufemismo, o qualitativo de 'boa tarifa'" (Cavalcanti, 1903:36).

Mesmo para Amaro Cavalcanti, as "necessidades do Tesouro"vinham em primeiro lugar; e só depois de avaliadas e sopesadas seria possível formular uma política tarifária para "dar a proteção aduaneira,já como elemento de fomento às indústrias nacionais no caso de bem merecêla" (Cavalcanti, 1903:38).

Por outro lado, Cavalcanti assinalava que dar proteção temporária e seletiva, não significava adotar uma política que poderia ser alterada ou extinguida ao bel-prazer dos políticos, pois,"dar hoje proteção aduaneira à certa indústria e, amanhã, diminuí-la, retirá-la mesmo, antes da possibilidade de alcançar o efeito desejado - sem o devido critério, ou pela simples razão de desagravar o imposto - comojá se tem feito entre nós; - é erro condenável, prejudicialíssimo, sobretudo, ao capital" (Cavalcanti, 1903:39). 
Embora afirmasse que a proteção só deveria ser estendida a algumas indústriaS, Amaro Cavalcanti não concordava com a teoria muito em voga na última metade da década de 1890, que contrapunha"indústrias naturais a indústrias artificiais" (Luz, 1978:84-85). Para os livre-cambistas, como Joaquim Murtinho, o grande inimigo das indústrias artificiais, as indústrias naturais eram as que podiam se desenvolver sem qualquer proteção governamental, e as indústrias artificiais as que utilizavam matérias-primas importadas, e que não podiam dispensar a proteção do Estado.

Amaro Cavalcanti discordava deste modo de ver a questão como deixou claro num artigo de 1903:

"Ele [o critério definido pelos livre-cambistas] pressupõe o Universo dividido em países, cada um deles com certas aptidões naturais e exclusivas, nos homens e nas coisas, e de tal modo ajustadas no tempo e no espaço - que a prosperidade de cada povo se faria sem outra condição, que não fosse a simples aplicação do seu capital e trabalho ao desenvolvimento das suas indústrias naturais." (Cavalcanti, 1903:12)

A primeira dificuldade para adotar este critério era a de saber quais eram as indústrias verdadeiramente naturais de um país. Mas, de todo modo, no seu entender, como mesmo as indústrias naturais não podiam dispensar certo grau de protecionismo, já que não eram exclusivas de um determinado país, a distinção não procedia.

"Suponham-se dois Estados limítrofes nessas condições naturais de identidade ou quase identidade - um tendo começado mais cedo e se achandojá com sua indústria natural em situação próspera e largamente desenvolvida, e outro, ao contrário, por ter começado mais tarde ou por acidente diverso, se achando apenas com a sua indústria em estado incipiente...

Naturalmente, dada inteira liberdade de concorrência, o primeiro desses países invadirá os mercados do segundo e,pela sua superioridade de condições produtoras e de experiência, não tardará em assenhorearse dos referidos mercados, isto é - levará a indústria incipiente do segundo Estado à completa ruína c desaparecimento. E como, agora, remediar a sorte desgraçada do último, continuando ele no mesmo regime de livre-câmbio?" (Cavalcanti, 1903:13) 
Segundo Cavalcanti, este mal, perfeitamente possível de ocorrer, principalmente no caso de um país novo como o Brasil, era a prova clara da fragilidade da teoria dos livre-cambistas," além de um desmentido formal à sua afirmativa categórica, de que as indústrias naturais são sempre capazes de fazer a prosperidade do país, dispensada toda e qualquer proteção oficial". Para Amaro Cavalcanti a tese sobre a indústrias naturais só seria verdadeira se "as aptidões e elementos naturais dos diferentes países se achassem por tal modo repartidos", de forma que um país produzisse aquilo que o outro necessitasse e não pudesse produzir por si mesmo (Cavalcanti, 1903:13-14).

\section{O Estado explorando indústrias}

Com relação à intervenção direta do Estado nas explorações industriais, Amaro Cavalcanti, como adepto da teoria liberal de Adam Smith e Stuart Mill, admitia uma intervenção direta do Estado em áreas ou setores essenciais em que a iniciativa privada não quisesse ou não pudesse investir. Assim afirmava: o Estado "não só pode, como até deve, tomar a si a exploração de certas indústrias, já no interesse imediato do serviço público e já no pensamento de desenvolvê-las no país, quando as forças individuais se mostrarem insuficientes ou incapazes de bem fazê-las" (Cavalcanti, 1896:132).

Todavia, as explorações industriais estatais deveriam obedecer a duas condições básicas: a) que as indústrias exploradas fossem de interesse geral para a coletividade e para o progresso do País e,b) que não se prejudicasse os interesses da iniciativa privada. Somente nessas condições a exploração industrial do Estado traria algum benefício para a sociedade.

Segundo Amaro Cavalcanti, geralmente, as razões que levavam o Estado à exploração industrial eram de três ordens: primeiro, o intuito de receber renda; segundo, a necessidade de garantir certos serviços especiais para a sociedade; e terceiro, a idéia de concorrer para o progresso real e prosperidade da nação. Na sua posição em defesa da industrialização, Cavalcanti considerava boas e interligadas as três razões, ou seja, o desenvolvimento de uma indústria poderia servir não apenas para atender as necessidades da sociedade, como para promover o progresso real da nação e ainda resultar em receitas para o Tesouro.

A exploração industrial pelo Estado deveria dar-se não apenas naqueles ramos onde a iniciativa privada não pudesse ou não tivesse interesse em investir, mas ainda em setores estratégicos. Sobre isso dizia: 
"Não lhe incumbindo o papel de criar a riqueza diretamente, em regra, ele só devia praticar aquelas indústrias, que, embora reconhecidamente indispensáveis ao país, deixassem, todavia de existir pela insuficiência dos recursos individuais. Além destas, em tais circunstâncias, outras há, que, o Estado pode ou deve mesmo exercê-las: são aquelas do interesse imediato de alguns ramos do público serviço, como por exemplo: a fabricação de moeda, a de instrumentos militares, ou de certas espécies de material bélico, como a pólvora, etc; assim como, razões manifestas de ordem, de garantia e de fiscalização lhe dão preferencia para o serviço do Correio, e dos Telégrafos, e não falta quem pense, que assim deveria também ser, a respeito das estradas de ferro em geral." (Cavalcanti, 1890:12)

Sendo assim, ação do Estado nas explorações industriais deveria ser auxiliar ou supletiva, atuando naqueles setores de inteira utilidade pública $e$ onde os recursos da iniciativa privada não bastassem para o seu desenvolvimento (Cavalcanti, 1892:322).

Por outro lado, Amaro Cavalcanti, como liberal convicto, ressaltava que a participação do Estado nas explorações industriais deveria ser apenas circunstancial, para atender as necessidades prementes da economia; no momento oportuno as empresas administradas pelo Estado deveriam passar para as mãos da iniciativa privada, pois o Estado, no seu entender, não era um bom administrador. Assim dizia:

"as indústrias ou serviços que um Estado pode ou deve iniciar e exercer no seio de uma nação nova e desprovida de instrução, de saber profissional, ou de capitais disponíveis, não devem, só por isso, ser continuadas indefinidamente por conta dos cofres públicos."

Enfim, o Estado poderia usar de todos os meios que dispunha para auxiliar e promover o desenvolvimento industrial do país, mesmo que a princípio isto significasse prejuízo aos cofres públicos, pois o desenvolvimento industrial e o retorno que a industrialização traria para a sociedade, quando elajá estivesse plenamente estabelecida, compensaria todos os "sacrifícios" iniciais, ou seja, neste caso, os fins justificariam os meios.

\footnotetext{
${ }^{10} \mathrm{Na}$ sua opinião o Governo já deveria ter se retirado de vários setores como, por exemplo, o das estradas de ferro. A. Cavalcanti, Elementos de Finanças, Estudo Theorico e Prático, Rio de Janeiro: Imprensa Nacional, 1896, p. 134.
} 
Outro argumento reiterado a longo do tempo por Amaro Cavalcanti, ao lado das políticas alfandegárias protecionistas para as indústrias, era a necessidade da adoção de uma política creditícia que viabilizasse maiores facilidades na obtenção dos recursos necessários para os novos investimentos, ou seja, facilidades de crédito, na forma de empréstimos diretos ou através da emissão fiduciária. No seu pensamento industrialista a moeda apresentava-se como uma das peças fundamentais da política econômica,pois no seu entender,"o capital era a alma mater da indústria" (Cavalcanti, 1892:324), esta necessitava de muito capital para se desenvolver e, portanto, de uma moeda forte e eficiente, capaz de atrair capitais para serem investidos em novos empreendimentos."

Em conseqüencia acreditava ser o saneamento monetário e fiscal do país um passo indispensável à aplicação de uma política industrialista. Contudo, o saneamento monetário para um país novo como o Brasil, sem recursos para investir e com dificuldades financeiras, só seria possível através da adoção da moeda fiduciária. No âmbito das discussões sobre os problemas monetários, e da polêmica que opôs na virada do século papelistas e metalistas, Amaro Cavalcanti se insere entre os denominados papelistas. Foi mesmo um dos raros autores que defenderam explicitamente o papel-moeda como a solução para os problemas da economia brasileira. ${ }^{12}$

Amaro Cavalcanti inspirava-se no modelo norte-americano que, em 1862, abandonou a conversibilidade, por ocasião da Guerra de Secessão, e autorizou os bancos nacionais a emitirem o papel-moeda, aumentando a oferta monetária. Segundo ele, o resultado dessa política teria sido "a maior prosperidade industrial e econômica, quejamais se viu em povo algum e uma solidez financeira invejável", o que possibilitou que o país voltasse a adotar moeda metálica anos depois, em 1879. E ainda acrescentava:

Amaro Cavalcanti foi um grande conhecedor da matéria financeira, e parte de suas obras constituem análises exaustivas do sistema financeiro brasileiro durante o Império e primeiros anos da República, que contribuem com uma descrição detalhada do funcionamento do meio circulante nestes períodos e retratam uma grande preocupação com a moeda nacional. Seus principais trabalhos nesta área são Resenha Financeira do Ex-Império do Brasil, de 1890, e O Meio Circulante Nacional, de 1893.Ver a respeito Suzana C. Fernandes, Amaro Cavalcanti e a Luta pela Industrialização Brasileira, op. cit., capítulo 3 .

Para a posição oposta, ver Pandiá Calógeras, A Política Monetária do Brasil. Tradução de Thomaz Newlands Neto, São Paulo: Cia Editora Nacional, 1960, p.199-215. 
"Não é preciso dizer como se operou este último milagre: é fácil de ver, que a barateza do dinheiro bancário para todas as indústrias trouxe o engrandecimento descomunal da produção, e que esta, exportada para os mercados estrangeiros, fez vir daí, em troca, a moeda dos outros povos, não como empréstimo, mas como riqueza própria do país. Por pouca que seja a vista do observador, se aperceberá que a nossa situação atual é, feitos os descontos, assaz semelhante: nós precisamos hoje de dinheiro, muito dinheiro em movimento, para satisfazer aos vários reclamos econômicos das nossas condições." (Cavalcanti, 1890:62)

Para Cavalcanti, o Brasil do final do Império encontrava-se na mesma situação dos Estados Unidos, pois também precisava de muito dinheiro em movimento para satisfazer as necessidades econômicas e para investir em empreendimentos industriais. E a moeda fiduciária era o único meio eficaz de prover o País dos recursos financeiros suficientes para fomentar seu progresso econômico. Mais tarde, com o desenvolvimento progressivo da sua economia, o País poderia adotar sem restrições o sistema de conversão metálica, mas no momento vivido, seria mais vantajoso para o progresso adotar a mesma política dos Estados Unidos, autorizando a emissão bancária garantida por títulos da dívida pública.

Para os papelistas, a moeda fiduciária, emitida pelos bancos, teria a vantagem de baratear o crédito, facilitando o investimento na produção industrial; esta, por sua vez, aumentando a produção nacional possibilitaria a diminuição das compras no exterior e o aumento do produto exportável, o que traria para o País mais divisas, não como empréstimo, mas como riqueza própria.

Além de ser um excelente instrumento de crédito público ou privado, a moeda fiduciária era um eficiente agente circulante de valores, que, segundo Cavalcanti (1983:9-10), desempenharia eficazmente as funções de moeda, por ser abundante e perfeitamente elástica. O resultado desta política seria um saldo favorável na balança de comércio, uma redução da dívida pública externa e o equilíbrio das finanças públicas, o que implicaria num certo equilíbrio no balanço de pagamentos e uma menor pressão sobre o câmbio, o que, consequentemente, favoreceria a boa imagem do país no exterior, atraindo mais trabalho e mais capital para serem investidos no País.

O pensamento de Amaro Cavalcanti sobre a moeda e o crédito era dos mais inovadores, pois ele teve a ousadia de poucos, de defender para o Brasil um sistema monetário mais liberal, baseado na moeda fi- 
duciária, num momento em que a maioria conservadora dos políticos queria adequar a economia brasileira às regras do padrão-ouro. ${ }^{13} \mathrm{Ca}-$ valcanti escreveu sua defesa da moeda fiduciária antes que Rui Barbosa tentasse a reforma monetária expansionista, baseada na emissão fiduciária, que favoreceu o surto industrial dos primeiros anos da República."

$\mathrm{Na}$ avaliação que fazia do sistema financeiro nacional durante todo o Império e primeiros anos da República, Amaro Cavalcanti chegava à conclusão que faltava ao Brasil um sistema monetário eficiente e adequado às circunstâncias internas do País, capaz de garantir um meio circulante abundante e o crédito farto para serem investidos no desenvolvimento da produção nacional. Na sua opinião, a estrutura produtiva do País ao longo de todo o Império e nos primeiros anos da República, não lhe permitia adequar-se às regras do padrão-ouro e manter a conversão metálica, sem que disso adviessem graves prejuízos, mas, a despeito disto, os governos insistiam em manter uma política conservadora seguindo a meta da conversibilidade. Para Cavalcanti, esta mentalidade conservadora era responsável por todos os problemas monetários e financeiros do Brasil - ou seja, pelo sistema monetário arcaico e deficiente, pela moeda depreciada, pela dívida pública crescente e pela insuficiência do meio circulante e do crédito para serem investidos no desenvolvimento da produção nacional.

Amaro Cavalcanti (1892:209) considerava que para adotar a conversão metálica com sucesso, o Brasil precisava primeiro desenvolver suas forças produtivas, aumentar sua produção para depender menos das importações e gerar maior riqueza interna; somente assim poderia ter o ouro necessário para manter a circulação metálica e garantir sua independência externa. Ou seja, fazia-se primeiro necessário aumentar os investimentos na produção nacional através da expansão do crédito, para somente depois, com o crescimento da produção e da riqueza interna e, conse-

Ver C.M. Pelaez,"As conseqüências econômicas da ortodoxia monetária, cambial e fiscal no Brasil entre 1889-1945", Revista Brasileira de Economia 25 (3), p. 5-82, ju1./ set. 1971. Especialmente p. 13 a 18 sobre a reforma de Rui Barbosa.

14 Lei de 17 de janeiro de 1890. Assim Calógeras comentava esta lei: "Estabeleceu-se o seguinte dilema: a emissão dos bancos era indispensável: não podendo fazê-la baseada no ouro, cumpria aceitá-la tendo como garantia os títulos da dívida pública. E sobre essa estranha concepção da natureza e função da moeda, o método de garantir uma dívida mediante outra dívida, foi considerado a solução científica do problema da circulação no Brasil." Pandiá Calógeras, ob. cit., p. 208. A. Cavalcanti defendeu no Congresso e nas suas obras a reforma de Rui Barbosa, pois esta se coadunava com as suas idéias. Cf. Resenha Financeira... ob. cit..passim. 
quentemente, da menor dependência externa, adotar-se a circulação metálica. Assim dizia:

"Tenhamos por verdade iniludível: enquanto a situação econômica do país for tal que dependamos, quase totalmente, da importação de produtos estrangeiros, para os objetos necessários às artes, às ciências, às indústrias, à habitação, ao vestuário e à própria alimentação quotidiana, não poderemos contar com a probabilidade prática, constante de circulação metálica. O valor do nosso meio circulante ficará sempre dependente do nosso desequilíbrio anual nas contas, que tivermos de saldar no estrangeiros." (Cavalcanti, 1892:232)

Rui Barbosa, embora fosse um metalista, também achava que o Brasil não estava preparado para a adoção do sistema metálico, devido à sua incompatibilidade com os problemas apresentados pelo nosso balanço de pagamentos. ${ }^{15}$ De acordo com ele, primeiro era preciso restabelecer o equilíbrio do balanço de pagamentos, para depois adotar a circulação metálica. Ou, como dizia, "não é (...) a circulação metálica que nos há de firmar o câmbio alto; é, pelo contrário, a estabilidade do câmbio ao par, efeito da prosperidade econômica da nação, que nos há de permitir a circulação conversível. Os metalistas invertem os termos do problema e, por isso, suas criações não passam de castelos de cartas" (Barbosa, 1892:29).

Mas, esta não era a opinião dominante no período, os metalistas representavam grande parte dos parlamentares e faziam oposição ferrenha a qualquer medida que procurava desvincular a política monetária da política cambial (Franco, 1983:103). Eles contestavam qualquer indicação de que havia escassez de moeda, e culpavam o excesso de emissão pela depreciação cambial. Ao longo de quase todo o Império e Primeira República, as idéias conservadoras prevaleceram no cenário político do Brasil, tentando implementar, na maioria das vezes sem sucesso, uma política monetária ortodoxa com objetivo de adequar o País às regras do padrão-ouro.

O debate em torno do meio circulante marcou boa parte da década de 1890 , mas, os discursos e as orientações de Amaro Cavalcanti e dos demais papelistas, de modo geral, não foram suficientes para conter o

Rui Barbosa realizou urna estimativa sobre o déficit no balanço de pagamentos brasileiro no fim do Império, que está em Do relatório Ruy Barbosa (1890), p. 540, apud. C.M. Pelaez,"As conseqüências econômicas da ortodoxia monetária, cambial e fiscal no Brasil entre 1889-1945", op. cit., p. 14. 
avanço das políticas econômicas ortodoxas vis-à-vis a condução da economia pela ala conservadora.

\section{Considerações finais: o industrialismo de Amaro Cavalcanti em perspectiva histórica}

As primeiras manifestações nacionalistas ocorreram entre nós no final do século XIX. Nos seus começos, o pensamento nacionalista confundiu-se com uma forma de industrialismo. Os primeiros homens de empresa ou políticos que colocaram os problemas brasileiros em termos da necessidade do desenvolvimento da indústria nacional acreditavam que a execução de uma política protecionista incentivaria a produção de manufaturados e tornaria o País menos dependente das importações estrangeiras. Amaro Cavalcanti foi sem sombra de dúvidas um dos mais ilustres representantes desta corrente. ${ }^{16}$ Procurou intervir nos temas propostos pela sua época: protecionismo versus livre-cambismo, papelistas versus metalistas, indústrias artificiais versus indústrias naturais, sempre tendo em vista o fortalecimento do Estado, do País, da nação. Polêmico sustentou algumas idéias muito controvertidas para a sua época. Defendeu a emissão fiduciária, que contrariava os princípios tradicionais da política econômica seguida no Império; defendeu a diversificação do crédito para novos setores, especialmente para as indústrias nacionais, contrapondo-se à política do antigo regime de auxiliar exclusivamente a agricultura; e, o que era ainda mais ousado, foi contrário aos próprios auxílios para a lavoura cafeeira. Criticava o papel subordinado no comércio internacional a que nos relegava a excessiva dependência do setor agrícola. Por outro lado, não poupava críticas a o setor do comércio, principalmente o comércio importador, considerado parasita e ganancioso, sempre disposto a frear o desenvolvimento industrial do Brasil, opondo-se às campanhas protecionistas.

\footnotetext{
Nos anos 1920, surgiria uma nova corrente nacionalista crítica do protecionismo e de certos efeitos do crescimento industrial urbano, como a elevação cada vez maior do custo de vida. Alberto Torres foi um dos expoentes desse pensamento nacionalista, que encarava com desconfiança a crescente urbanização da economia e defendia a volta às bases da vida rural. Por outro lado, gradualmente, para os nacionalistas agraristas e para os nacionalistas industrialistas os Estados Unidos deixam de ser o modelo a imitar à medida que desenvolvem uma política imperialista na América Latina. Cf.Ligia Osório Silva,"A crise no quadriênio Bernardes:repercussões políticas do 'caso da Itabira Iron'", in: De Lorenzo, H.C e Costa, W. P. (org.) A Década de 1920 e as Origens do Brasil Moderno. São Paulo: Fundação Editora da Unesp/Fapesp, 1997, p.15-35.
} 
Embora não possamos dizer que estivesse certo em todas as suas afirmações, devemos ressaltar que suas idéias econômicas e financeiras apresentavam a coerência de quem conhecia profundamente as finanças públicas e, mais do que isso, de alguém que reconhecia as deficiências da economia nacional e lutava para eliminá-las. Sob a aparência de lutar pela adoção de políticas circunstanciais, a análise de Cavalcanti punha o dedo em problemas de longo prazo da economia brasileira, problemas que continuaram a ser debatidos ao longo de todo o século XX, e que consistiam, sobretudo, na questão do atraso econômico e da dependência.

Algumas de suas idéias resistiram à passagem do tempo e podem ser vistas hoje como prova do seu conhecimento sobre assuntos econômicos e da sua capacidade de aprender com o exemplo de outros países. Sem dúvida a crítica que fez da adoção do padrão-ouro nas circunstâncias nas quais se encontrava o Brasil era uma dessas idéias. A insistência com a qual incitava o Estado brasileiro a investir na melhoria dos meios de transportes e na remoção das barreiras alfandegárias que tanto atrasaram a formação do mercado interno são outras das suas propostas que não envelheceram.

Por outro lado, é forçoso observar que sob certos aspectos suas críticas tinham um caráter perfunctório.

Amaro Cavalcanti acreditava que a única forma de desenvolver economicamente o País, de reverter seu atraso econômico e garantir a soberania nacional, era fomentando o seu desenvolvimento industrial. Para ele, a indústria era "a classe produtora por excelência" e, portanto, deveria ser estimulada e protegida pelo Estado.

Seu raciocínio era bastante simples, estimulando seu desenvolvimento industrial, o País poderia substituir as importações pela produção interna, o que acarretaria uma diminuição do volume de importações, bem como dos encargos relacionados ao processo de importação (fretes, seguros, etc). Além disso, a produção industrial poderia vir a compor a pauta de exportações nacionais, melhorando ainda mais o saldo de nossa balança comercial e, ainda, poderia garantir uma renda maior para os cofres públicos, gerados pela tributação sobre a própria produção. Segundo Amaro Cavalcanti, o resultado desse processo seria, o equilíbrio do balanço de pagamentos do País. Esse equilíbrio tanto se daria pelo aumento do saldo da balança comercial, como pela diminuição dos empréstimos externos usados para cobrir os déficits.

Contudo, esta sua lógica merece alguns reparos. Em primeiro lugar, a idéia de que a industrialização resolveria os problemas do balanço de pagamentos é um tanto questionável, principalmente analisando-se o 
processo de substituição de importações no curto e médio prazos. Industrializar o Brasil naquele momento implicaria, necessariamente, em importar máquinas e equipamentos para a instalação das fábricas e, dado o elevado custo destes equipamentos no mercado internacional, certamente implicaria em ônus de grandes proporções para a nossa balança comercial. ${ }^{17}$ Em segundo lugar, deve-se considerar que levaria um certo tempo até que estas indústrias começassem a produzir o suficiente para suprir o mercado interno, diminuir as importações e gerar receitas para o Governo. E, por último, encontrar um nicho no mercado mundial para produtos industrializados, numa época em que os países europeus e os Estados Unidos "defendiam" seus mercados internos não era tarefa tão simples quanto ele parecia acreditar. Entretanto, a lógica do seu argumento era irrepreensível a longo prazo.

$\mathrm{Na}$ comparação do desenvolvimento do Brasil com o dos Estados Unidos, Cavalcanti também não ultrapassava um certo nível de superficialidade:hmitava-se a enxergar as políticas tarifárias e monetárias como o grande diferencial. Não mencionava o fato de que, em plena Guerra Civil, o governo dos Estados Unidos fez aprovar uma série de outras medidas ao mesmo tempo em que reforçava o protecionismo em torno das suas indústrias. Foram elas: a tarifa Morrill (1861) que aumentou os impostos sobre as importações preparando o terreno para uma legislação de altas tarifas depois do fim da guerra; a lei sobre a posse da terra (Homestead Act, 1862) que estabelecia a distribuição de terras no Oeste de forma quase gratuita e que representou um poderoso estímulo à colonização do Oeste, atraindo um enorme fluxo migratório; a lei dos bancos nacionais, que fez com que o sistema monetário provesse uma oferta limitada, mas eficiente, de moeda; e, finalmente as leis das Ferrovias do Pacífico $(1862,1864)$ que colocaram à disposição subsídios federais para ferrovias transcontinentais (Fusfeld, 2001:102). Em outros termos, ele não empreendeu a análise do conjunto das políticas americanas e das possibilidades reais do Brasil seguir o mesmo caminho.

De outro ângulo, observa-se um certo viés "institucionalista"18 na

${ }^{17}$ Os bens de capital importados da Grã-Bretanha, por exemplo, representaram 36,79\% do total das importações no período $1890-94,38,96 \%$ no período $1895-99,41,60 \%$ no período 1900-04 e 41,79\% no período 1905-09. Richard Graham, Britain and the Onset of Modernization in Brazil, 1850-1914, Cambridge:University Press, 1968,p. 135.

${ }^{18} \mathrm{O}$ "institucionalismo" foi revivido recentemente nos trabalhos de Douglas North, especialmente Institutions, Institucional Change and Economic Performance, New York, 1990. North procurou explicar a crescente diferença de desempenho econômico observada entre os países avançados e os subdesenvolvidos e chegou à conclusão de 
sua visão da sociedade. Aparentemente, ele considerava suficiente a formulação de uma política econômica adequada para que a sociedade brasileira, que emergira havia tão pouco tempo do escravismo predominante durante todo o Império, superasse os obstáculos que se interpunham no caminho da industrialização. Em outros termos, aparentemente Amaro Cavalcanti trabalhava com a noção de uma classe política autônoma e capaz de implementar qualquer tipo de política, uma vez que estivesse convencida da sua validade. Um bom repertório de leis e algumas mudanças na cultura política do País seriam suficientes para modificar a inclinação agrária da sociedade brasileira e colocá-la nos trilhos da industrialização.

As classes que defendiam os interesses agrários, e que estiveram desde cedo presentes na organização do Estado Republicano, também chamadas de oligarquias agrárias, procuravam uma forma de inserção da economia brasileira na economia mundial que conflitava, na prática, com os planos industrializantes de Amaro Cavalcanti. Por outro lado, os capitais necessários às indústrias, assunto recorrente nos seus escritos, vieram, em alguma medida, do setor agrário, quando foi preciso diversificar os investimentos. A relação entre a expansão do setor exportador e o desenvolvimento industrial é uma das questões mais debatidas pela historiografia econômica brasileira. ${ }^{19}$ As conclusões do trabalho de Sérgio Silva sobre a origem das indústrias, por exemplo, levam a descartar qualquer relação unívoca entre a expansão do setor exportador e a continuidade do crescimento industrial. O setor industrial esteve nesse período subordinado à economia cafeeira, sofrendo em conseqüencia os efeitos das alterações ocorridas nesta, mas esses efeitos ora representaram estímulos, ora constituíram obstáculos. Aparentemente Amaro Cavalcanti enxergou apenas os obstáculos interpostos no caminho da industrialização e, assim fazendo, subestimou as forças concretas da sociedade, a mesmo tempo em que exagerava o papel que o Estado e os políticos desempenhariam na mudança que estava ocorrendo (Silva, 1995).

que o problema se encontra nas instituições, isto é, nas "regras do jogo" que estruturam, incentivam ou bloqueiam a atividade econômica.A estrutura institucional é composta pelas leis constituídas pelos aspectos culturais e pelos mecanismos que obrigam o cumprimento dos contratos e direitos de propriedade.

${ }^{19}$ Para uma visão de conjunto do debate sobre a origem das indústrias e uma discussão atualizada do papel da economia exportadora no crescimento do setor industrial ver Wilson Suzigan, Indústria Brasileira, Origem e Desenvolvimento, São Paulo: Hucitec/ Unicamp, 2000, principalmente os capítulos I a III. 
Por último, resta-nos situar a posição que ocupam as idéias econômicas de Amaro Cavalcanti na história do pensamento. Com certeza era adepto do liberalismo econômico, mas jamais poderia ser acusado, como faz equivocadamente Dorival TeixeiraVieira, de "pioneiro do neoliberalismo" Isto porque, bastante bem informado sobre o que acontecia no resto do mundo Amaro Cavalcanti tinha clareza de que o desenvolvimento econômico reservava um papel cada vez mais importante ao Estado, principalmente no caso dos países que haviam acumulado um certo atraso - causado no caso brasileiro, sobretudo, pela demora em abolir a escravidão. Defendia a proteção tarifária às indústrias, de modo seletivo e temporário, como forma de superar o atraso e incentivar a conversão da vocação agrária do país. E fazia-o dentro de uma forte convicção nacionalista de que a industrialização era a única forma de garantir um futuro próspero para a nação. Neste sentido, pode ser melhor caracterizado como um "pioneiro do desenvolvimentismo".

\section{Bibliografia}

Augusto José. Amaro Cavalcanti. Rio de Janeiro: Departamento Administrativo do Serviço Público, 1956.

Bairoch, Paul. Economics and World History. Myths and Paradoxes. New York: Harvester/ Wheatsheaf, 1993.

Barbosa, Rui. Finanças e Políticas na República - Discursos e Escriptos de Rui Barbosa. Capital Federal: Companhia Impressora, 1892.

Bastos, Humberto. O Pensamento Industrial no Brasil (introdução à história do capitalismo industrial brasileiro), São Paulo, 1952.

Calógeras J. Pandiá. A Política Monetária do Brasil (1910), Trad.Thomaz Newlands Neto, São Paulo: Cia. Ed. Nacional, 1960, Brasiliana: Série Grande Formato, vol. 18.

Carone, Edgard. O Pensamento Industrial no Brasil (1889-1945), São Paulo: Difel, 1977. Correa, Serzedelo. O Problema Econômico no Brasil, 1903. Brasília: Senado Federal, 1980. Encyclopédia e Dicionário Internacional, vols. II e IV,W. M. Jackson Editora, Rio de Janeiro, s/d.

Fernandes, Suzana Cristina. Amaro Cavalcanti e a Luta pela Industrialização Brasileira. Dissertação de Mestrado. Campinas, Instituto de Economia/Unicamp, 2001.

Franco, Gustavo. Reforma Monetária e Instabilidade durante a Transição Republicana, Rio de Janeiro: BNDES, 1983.

_"A Primeira Década Republicana", in Abreu, Marcelo Paiva et alii, A Ordem do Progresso: Cem anos de Política Econômica Republicana, 1889-1989. Rio de Janeiro: ed. Campus, 1989, p.11-30.

Fursfeld, Daniel. A Era do Economista. São Paulo: Saraiva, 2001.

Graham, Richard. Britain and the Onset of Modernization in Brazil, Cambridge: University Press, 1968 .

${ }^{20} \mathrm{O}$ epíteto seria adequado se aplicado a Joaquim Murtinho, Darwinista social convicto, que enquanto integrante dos governos Prudente de Morais e Campos Sales se opôs à idéia de previdência social. Cf. Richard Graham, ob. cit., p.245 
Lima, Heitor Ferreira. História do Pensamento Econômico no Brasil. $2^{a}$ ed. São Paulo: Ed.Nacional, 1978 .

List, G.. Friedrich. Sistema Nacional de Economia Política. Apresentação de Cristóvam Buarque e Tradução de Luiz João Baraúna. 2a ed. São Paulo: Nova Cultura, 1986.

Luz, Nícia Vilela. "Aspectos do nacionalismo econômico brasileiro (III): esforços em prol da industrialização". Revista de História 34, out.-dez. 1958, p. 305-333.

A luta pela Industrialização no Brasil. 2. ed. São Paulo: Alfa Omega, 1978

Marcondes, Renato L."Padrão-Ouro e Estabilidade", in: Estudos Econômicos. São Paulo, V. 28, N. 3, P. 533-559, Jul.-Set./1998.

North, Douglas. Institutions, Institucional Change and Economic Performance. New York, 1990.

Pelaéz, C. M."As conseqüências econômicas da ortodoxia monetária, cambial e fiscal no Brasil entre 1889-1945". Revista Brasileira de Economia 25 (3),p. 5-82,jul./set. 1971. Revista do Instituto Histórico c Geográfico Brasileiro. Tomo 92, vol. 146, (1922), pg. 592594, Rio de Janeiro: Imprensa Nacional, 1926. Tomo LX, Parte I $\left(1^{\circ}\right.$ e $2^{\circ}$ trimestres $)$, p366 a 375 e 407 a 413, Rio de Janeiro: Imprensa Nacional, 1897. Tomo LXXV, Parte II (1912), p. 241

e 280, Rio de Janeiro: Imprensa Nacional, 1913.

Silva, Lígia M. Osório, "A crise no quadriênio Bernardes: repercussões políticas do 'caso da Itabira Iron'", in:De Lorenzo, H. C. e Costa, W.P. (org.) A Década de 1920 $e$ as Origens do Brasil Moderno. São Paulo: Fundação Editora da Unesp/Fapesp, 1997, p. $15-35$.

Silva, Sérgio. Expansão Cafeeira e Origens da Indústria no Brasil. 8a. ed. São Paulo: AlfaOmega, 1995.

Sodré, Nelson Werneck. Introdução à Revolução Brasileira. São Paulo: Livraria Editora Ciências Humanas, 1978.

Suzigan, Wilson. Indústria Brasileira: Origem e Desenvolvimento. São Paulo: Hucitec/ Unicamp, 2000 .

Velho Sobrinho.J. F, Dicionário Biobibliográfico Brasileiro. Rio de Janeiro: Pongetti, 1937, vol. 1.

Vieira, Dorival Teixeira, A Obra Econômica de Amaro Cavalcanti. São Paulo: FEA/USP, Boletim n ${ }^{\circ} 16,1960$.

\section{Obras de Amaro Cavalcanti na área econômica}

"A vida econômica e financeira do Brasil", in: Annaes da Bibliotheca Nacional do Rio de Janeiro, Oficinas Gráficas da Biblioteca Nacional, 1920, vol. XXXVIII (Conferência realizada em 1914).

"Taxas Protectoras nas Tarifas Aduaneiras", in: Boletim da Sociedade Auxiliadora da Indústria Nacional. Rio de Janeiro, 1903, p. 3-39.

Elementos de Finanças. Estudo Theórico-Prático. Rio de Janeiro: Imprensa Nacional, 1896.

O Meio Circulante Nacional (1808-1835). Brasília: Editora Universidade de Brasília, 1983 (Coleção Temas Brasileiros 53) (Primeira publicação em 1893)

Política e Finanças. Rio de Janeiro: Imprensa Nacional, 1892 (Coletânea de Discursos de Amaro Cavalcanti no Congresso Nacional em 1891 e 1892)

Regime Federativo e República Brasileira. Brasília: Editora Universidade de Brasília, 1983 Coleção Temas Brasileiros, 48 (Primeira publicação em 1899)

Resenha Financeira do Ex-Império do Brasil. Rio de Janeiro: Imprensa Nacional, 1890. 